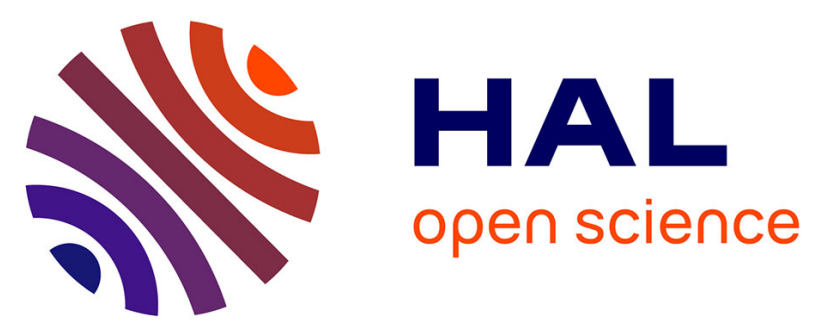

\title{
A strain rate and temperature dependent criterion to describe the linear - non linear behaviour's transition of organic matrix composite materials in shear: Application to T700GC/M21
}

M. Castres, J. Berthe, M. Brieu, E. Deletombe

\section{To cite this version:}

M. Castres, J. Berthe, M. Brieu, E. Deletombe. A strain rate and temperature dependent criterion to describe the linear - non linear behaviour's transition of organic matrix composite materials in shear: Application to T700GC/M21. Mechanics of Materials, 2018, 124, pp.100-105. 10.1016/j.mechmat.2018.06.002 . hal-01833139

\section{HAL Id: hal-01833139 \\ https://hal.science/hal-01833139}

Submitted on 9 Jul 2018

HAL is a multi-disciplinary open access archive for the deposit and dissemination of scientific research documents, whether they are published or not. The documents may come from teaching and research institutions in France or abroad, or from public or private research centers.
L'archive ouverte pluridisciplinaire HAL, est destinée au dépôt et à la diffusion de documents scientifiques de niveau recherche, publiés ou non, émanant des établissements d'enseignement et de recherche français ou étrangers, des laboratoires publics ou privés. 


\title{
A strain rate and temperature dependent criterion to describe the linear - non linear behaviour's transition of organic matrix composite materials in shear: Application to T700GC/M21
}

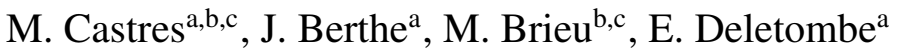 \\ ${ }^{a}$ ONERA-The French Aerospace Lab, F-59014, Lille Cedex, France \\ ${ }^{b}$ Univ Lille Nord de France, F-59000 Lille, France \\ ${ }^{c}$ Centrale Lille, LML, F-59650 Villeneuve D'Ascq, France
}

\begin{abstract}
The organic matrix composites (OMC) are widely used in aeronautical industry. The mechanical behaviour of these materials is known to be strain rate and temperature dependent. Therefore it is necessary to take the influence of temperature and strain rate into account in the behaviour models. The mechanical behaviour of OMC can be split into two different parts: a first linear and a second non linear phasis. To predict the evolution of the mechanical behaviour, it is important to evaluate the transition between linear and non linear behaviour with respect to the influence of the strain rate and the temperature. For this purpose, different strain rate and temperature dependent failure criteria and yield stress criteria, available in the literature were considered. These criteria were compared to the experimental results obtained in previous works [1]. Finally a strain rate and temperature dependent criterion was proposed to describe more accurately this transition evolution.
\end{abstract}

Keywords: Polymer-matrix based composite, Transition stress, Strain rate dependency, Temperature dependency

\section{Introduction}

Nowadays, the aeronautical industry has to face new challenges, in particular to reduce the weight of the aircraft (for environmental and cost reasons). One of the solution to reach targeted weight reductions is to use carbon fibre based composite materials. These materials also allow to avoid corrosion, to manufacture complex parts and to optimize the mechanical

Email address: magali.castres@onera.fr ()

${ }^{1}$ Corresponding author: M. Castres,

ONERA-The French Aerospace Lab, 5 Boulevard Paul Painlevé -BP21261, F-59014, Lille Cedex, France

Preprint submitted to Elsevier

July 5, 2018 
properties according to the loads while weight is reduced with respect to aluminium or metallic structures. One important issue in the aeronautic transport industry is to improve safety (see Flightpath 2050, Challenge 4). The main difficulty concerning this question relies on the severe conditions to which the aircraft can be exposed, including a large range of impacts and strain rates, under various operational temperature conditions. To be able to cope with this difficulty, it is important to better understand the mechanical behaviour of composite materials for every conditions aircraft may face, with the aim to model it to reduce the safety margins. Indeed an accurate and efficient model would lead to perform numerous structural analysis representative from real conditions, from static to dynamic loadings and for various temperatures.

The material studied in the present paper is a carbon fibre reinforced plastic one (CFRP), and particularly a carbon/epoxy composite: the T700GC/M21 and particularly the laminate $\left[ \pm 45^{\circ}\right]_{s}$. The mechanical behaviour of CFRP is known to be strain rate dependent [2-5], especially with shear loading $[4,6,7]$ and temperature dependent $[2,3,8]$. One important conclusion of these studies is that their mechanical shear behaviour can be decomposed into two different phasis: a first linear, a second non linear, followed by the final rupture of the material $[4,6,9,10]$. In the literature, different models can be found to describe the mechanical behaviour of these materials [11-14]. These models differ by the method used to model the non linear behaviour, some of them use a non linear viscoelastic spectral method and a damage model $[11,12,15]$, and others use a plasticity model and a damage model $[13,14,16]$. The linear behaviour of the T700GC/M21 material with respect to the influence of the temperature and the strain rate has already been studied by Berthe et al. [17, 18], who proposed a viscoelastic bi-spectral model to describe this linear behaviour. This behaviour once studied, the question arises of the transition between linear and non-linear behaviour. This transition can be evaluated in terms of stress $\sigma_{t}$ or strain $\varepsilon_{t}[1]$.

This works are focused on the shear transition between linear and non linear behaviour. The aim of the present works is to propose a strain rate and temperature dependent material model to describe the transition shear stress and strain $\left(\sigma_{t}\right.$ and $\left.\varepsilon_{t}\right)$ evolution laws for composite materials, such as T700GC/M21, based on the models available in the composites and polymers literature. For this purpose, an experimental investigation on the T700GC/M21 [ \pm 45$]$ laminate for a large range of strain rates and temperatures using an hydraulic jack has been used $[17,18]$. The $\sigma_{t}$ and $\varepsilon_{t}$ obtained in [1] were considered for modelling purposes. In a first step a strain rate dependent model is proposed. Then, the temperature dependence is added. The final model 
is compared to the experimental results.

\section{About the transition between linear and non linear behaviour}

To use the mechanical behaviour models $[11-14,16]$ it is important to define accurately the transition between the different phasis of the shear behaviour. To the authors knowledge, the value of the transition between linear and non-linear behaviour is usually characterised by inverse methods for a laminate $\left[ \pm 45^{\circ}\right]$. In previous works [1], a direct method to evaluate accurately this transition using only experimental raw data was proposed. In these works, the authors obtained this transition for six different strain rates at ambient temperature and for three different strain rates at $-40^{\circ} \mathrm{C}$ and $-100^{\circ} \mathrm{C}$. This transition is hereafter referred as $\sigma_{t} / \varepsilon_{t}$. In [1], the strain rate and temperature dependencies of this transition were established. Therefore to take into account this transition in a behaviour model, it is necessary to have a model of this transition which includes temperature and strain rate dependencies.

A brief overview of the results obtained in [1] is presented in the sequel, more details can be found in the original paper. The studied material was a $[ \pm 45]_{s}$ laminated composite made of four plies of M21 epoxy resin and T700GC carbon fibres which had been cured with a typical cure cycle. Tensile tests had been performed on a servo hydraulic jack for three different temperatures: $20^{\circ} \mathrm{C},-40^{\circ} \mathrm{C},-100^{\circ} \mathrm{C}$. At low temperatures, the temperature is controlled by a thermocouple. The regulation system used in the environmental chamber is a "Microcor III" system. To obtain a uniform temperature in the tested specimen, before performing the test, a stabilisation time is applied (about $10 \mathrm{~min}$ ). At ambient temperature six loading speeds between $8,3.10^{-6} \mathrm{~m} / \mathrm{s}$ and $2 \mathrm{~m} / \mathrm{s}$ were studied, for the two other temperatures three loading speeds were performed between $8,3 \cdot 10^{-4} \mathrm{~m} / \mathrm{s}$ and $0,5 \mathrm{~m} / \mathrm{s}$. For each material sample two strain gauges were glued on opposite faces of the specimens to measure the longitudinal and transverse strains. These tests were described in more details in $[1,18,19]$. For each test, the method described in [1] was applied and the transition between the linear and non linear behaviour, $\sigma_{t}$ and $\varepsilon_{t}$, was characterized. The obtained results are plotted in Figure 1.

In Figure 1, one may notice that the $\sigma_{t}$ and $\varepsilon_{t}$ values increased with the increasing strain rate and with the decreasing temperature, so the influence of the temperature and of the strain rate had been demonstrated. The next step consists in trying to model the transition evolution criterion with respect to the strain rate and the temperature. This is the aim of the next paragraph. 

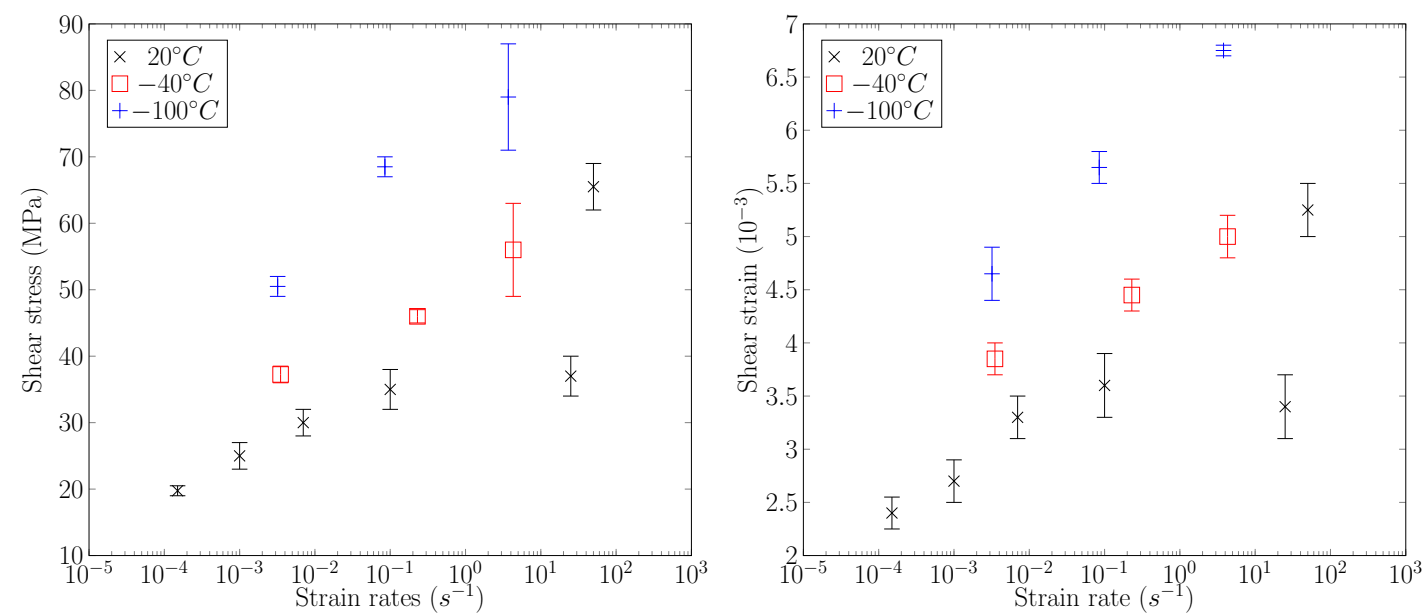

Figure 1: $\sigma_{t}$ and $\varepsilon_{t}$ at three different temperatures for $\left[ \pm 45^{\circ}\right]_{s}$ T700GC/M21

\section{The different strain rate and temperature dependent criteria of the literature}

To the authors knowledge in the composites literature, no strain rate and temperature dependent criterion has been yet proposed. Classically the two dependencies were considered separately.

\subsection{Strain rate dependent criteria}

There are at least three criteria in the composites literature, and in particular failure criteria, which are strain rate dependent [7, 20-22]. In their works, Daniel et al. [7, 20] proposed to model the influence of strain rate thanks to a linear logarithmic expression. A second criteria was proposed by Raimondo et al. [21]. These authors proposed to use the quadratic logarithm expression $\left(k=k_{0}+k_{1} * \log (\dot{\varepsilon})+k_{2} *(\log (\dot{\varepsilon}))^{2}\right.$ with $k_{0}, k_{1}, k_{2}$ being constants) to model this dependency. However, after identification Raimondo et al. showed that for a carbon epoxy / composite the constant $k_{2}$ was equal to zero. Therefore the criterion proposed by Raimondo et al. [21] is similar to the one proposed by Daniel et al. [7, 20]. These two criteria were proposed considering only three strain rates. In the presented works six different strain rates are available. In the Figure 2, the values obtained thanks to a linear logaritm expression such as proposed by Daniel et al. [7, 20] and Raimondo et al. [21] are compared with the experimental transition shear stress obtained in 2. A linear logarithm expression seems not to be sufficient to describe the evolution of the transition shear stress with the strain rates if all strain rates are considered. Furthermore, a linear logarithm dependency implies an infinite transition stress or strain when the strain rate increases, which is assumed not to be physical. 


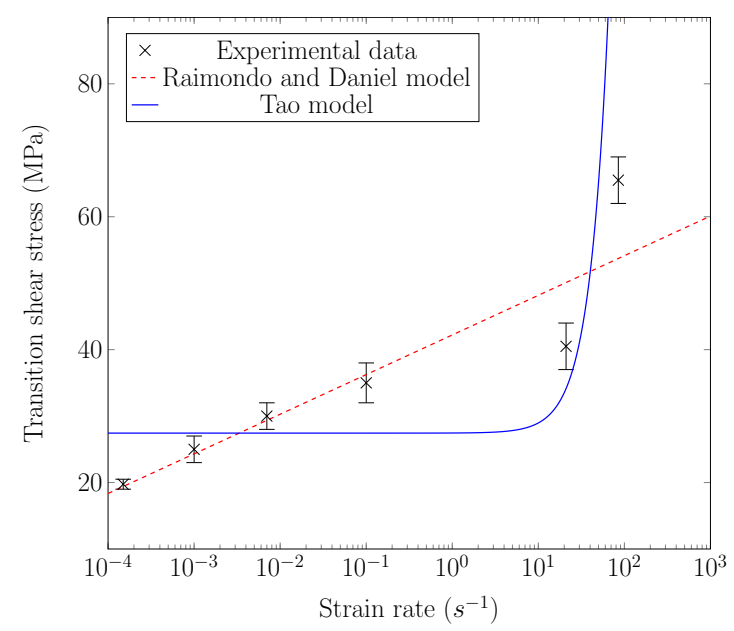

Figure 2: Comparison between experimental $\sigma_{t}$ of the T700GC/M21 at ambient temperature and models of the literature

The third criterion available in the composites literature was proposed by Tao et al. [22]. This criterion is a polynomial criterion. Such as the two other criteria, this criteria was proposed considering three strain rates. Moreover this kind of criterion implies an infinite transition stress or strain for high strain rates, which is assumed not to be physical. This criterion was applied to the experimental shear stress. The achieved results are plotted in Figure 2. One may noticed that this model does not seem to be sufficient to describe the evolution of the transition shear stress with the strain rates.

The three different criteria proposed in the literature do not describe the evolution of the transition shear stress or strain with the strain rates.

\subsection{Temperature dependent criteria}

The composite literature regarding the influence of temperature on various criteria is sparse. One initial approach would be to consider the influence of residual strain $\varepsilon^{\text {th }}$ due to the cure of the composite material. A common method to do so is to consider the thermal strain in the behaviour law [23]:

$$
\begin{aligned}
& \left.\underline{\sigma}=\underline{\underline{C^{0}}:}: \underline{\varepsilon^{T}}-\underline{\varepsilon^{t h}}\right) \\
& \underline{\varepsilon^{t h}}=\left(T-T_{0}\right)\left(\begin{array}{c}
\alpha_{1} \\
\alpha_{2} \\
0
\end{array}\right)
\end{aligned}
$$

Where $\underline{C^{0}}$ is the initial elastic stiffness, $\underline{\varepsilon^{T}}$ the total strain tensor, $T$ the test temperature and $T_{0}$ 
the stress free temperature. $\alpha_{1}$ and $\alpha_{2}$ are the thermal coefficients in the fibre direction and in the transverse direction.

To apply this method to the studied material, the viscoelastic bi-spectral model proposed by Berthe et al. $[17,18]$ is used as well as the results obtained in these works. The stress free temperature was taken from works of Huchette [24] and the thermal coefficient from works of Laurin [12] $\left(T_{0}=180^{\circ} \mathrm{C}, \alpha_{1}=-1.10^{-6} /{ }^{\circ} \mathrm{C}\right.$ and $\left.\alpha_{2}=26.10^{-6} /{ }^{\circ} \mathrm{C}\right)$. The stress tensor for each ply of the laminate were evaluated for four extreme configurations at ambient temperature for a quasi static test speed of $8,3 \cdot 10^{-6} \mathrm{~m} / \mathrm{s}$ and dynamic test speed of $2 \mathrm{~m} / \mathrm{s}$, and at $-100^{\circ} \mathrm{C}$ for a quasi static test speed of $8,3 \cdot 10^{-4} \mathrm{~m} / \mathrm{s}$ and dynamic test speed of $0,5 \mathrm{~m} / \mathrm{s}$. In this work, the linear behaviour is considered until the transition between linear and non-linear behaviour. Therefore the stress tensor was evaluated at the initial state of the test (for $\sigma_{11}=0$ ) and for the transition state (for $\sigma_{11}=\sigma_{11 t}$ experimentally evaluated). All the stress values evaluated in the transverse direction $\left(\sigma_{22}\right)$ were lower than the tensile transverse strength. This method does not seem to be adequate to describe the temperature dependency of the transition between linear and non-linear behaviour. Consequently, if a non linear behaviour is obtained, particularly at low temperature, the non linearity cannot be directly attributed to interfibre failure through a classical failure criterion.

The various criteria proposed in the composite literature appear not to be adequate to describe the evolution of the transition shear stress or strain with the strain rate and the temperature.

\section{Modelling the T700GC/M21 $\sigma_{t}$ and $\varepsilon_{t}$ evolution laws}

Regarding the different criteria of the literature, in a first step the strain rate dependency is considered.

\subsection{Modelling of the effect of the strain rate on the T700GC/M21 $\sigma_{t}$ and $\varepsilon_{t}$}

The criteria proposed in the composite literature are not sufficient to describe the evolution of transition shear stress or strain. In their works Boumbimba et al. [25, 26], Wang et al. [27] and Raimondo et al. [21] have shown that the mechanical shear behaviour of a composite material was strongly dependent on the matrix behaviour. Therefore the polymers literature was also considered, and more particularly the epoxy resin studies about the influence of the strain rate on yield stress or failure criteria. Gerlach et al. [28] and Jordan et al. [29] proposed 
to model the yield stress of an epoxy resin with respect to $\log (\dot{\varepsilon})$ by a bilinear criterion. But this solution also leads to an infinite yield stress or strain when the strain rate is infinite, which is assumed not to be physical. Therefore this solution was not studied. In their works Gerlach et al. [28] also proposed to model the influence of the strain rate on a strain failure criterion thanks to a model proposed by Goldberg [30]. The equation which was used was inspired from the Weibull distribution and can be summarized as:

$$
\varepsilon_{\text {fail }}=\varepsilon_{\text {ini }}+\varepsilon_{\text {diff }} *\left(1-\exp \left(c_{2} * \dot{\varepsilon}^{c_{3}}\right)\right)
$$

Where $\varepsilon_{i n i}$ is the initial failure strain, $\varepsilon_{d i f f}$ the difference between the failure strain in quasistatic and high rate experiments and $c_{2}, c_{3}$ the material constants.

This criterion is interesting because it leads to the saturation of the strain failure criterion for infinite strain rates. The criterion proposed by Gerlach et al. [28] was applied on the transition shear stress introduced in paragraph 2. The adapted equation of the Gerlach criterion is the following:

$$
\sigma_{t}=\sigma_{0}+\sigma_{\text {diff }} *\left(1-\exp \left(c_{2} * \dot{\varepsilon}^{c_{3}}\right)\right)
$$

As there was no available data at ambient temperature that reach the saturation value, an arbitrary value was taken which corresponds to the highest value obtained for all the tests including those at low temperature to obtain the $\sigma_{0}$ value. To identify the other parameters of the criterion, a least square optimization was done thanks to the PYTHON software. The obtained results are plotted in Figure 3.

One can notice that the Gerlach criterion seems to reach good agreement with the experimental data at high strain rates, but not at low strain rates. Indeed, in their works Gerlach et al. [28] identified their criterion for strain rates between $10^{-1} \mathrm{~s}^{-1}$ and $10^{3} \mathrm{~s}^{-1}$, therefore the range of strain rates used in Gerlach's works was less extensive than the one studied here. On the larger studied range of strain rates, many different mechanisms were involved. The strain rate dependent criterion proposed by Gerlach seems not to be sufficient to describe the evolution of the transition shear stress or strain with the strain rate. However, the Gerlach criterion is interesting because this model permit to obtain a saturation value of the stress when the strain rate increases. Moreover, this models seems to be in good agreement with experimental data at high strain rates. Therefore, it is proposed to adapt this model to describe the evolution of the transition shear stress or strain on the large range of strain rates studied. 


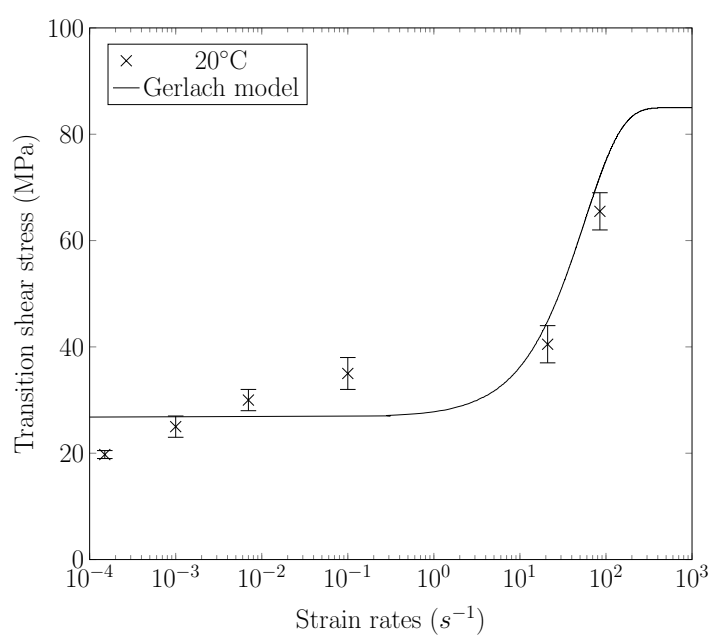

Figure 3: Application of the Gerlach criterion to the $\sigma_{t}$ limit at ambient temperature for T700GC/M21

To adapt the previous model the polymer literature is considered. In their works Jordan et al. [29] proposed to use a bi-sigmoidal criterion to describe the evolution of the elastic modulus of the epoxy resin with the temperature. In this last works the authors used the Decompose / Shift / Reconstruct method defined in $[31,32]$ to decompose the elastic modulus according to the mechanisms involved. According to the works of Jordan et al. [29] each sigmoid represents distinct mechanisms related to transition temperature, the $\beta$ transition for the sigmoid at low temperature and the $\alpha$ transition for the sigmoid at moderate temperatures. The $\alpha$ and $\beta$ mechanisms are phenomena resulting from the blocking of macromolecules mobilities. The $\alpha$ relaxation is called the main relaxation and is usually related to the glass transition [33]. The $\beta$ relaxation occurs for temperature lower than the glass transition. This $\beta$ relaxation is related to the molecular mobility of main chain and side groups [32], and in particular for epoxy resin to the relaxation of glyceryl or diphenlypropane groups [34]. Using the time-temperature equivalence, this bi-sigmoidal shape should also be found when the evolution of the elastic modulus with the strain rates was studied.

Regarding the modelling of the yield stress, some authors [35-37] have shown that two rheological mechanisms are necessary to completely describe the evolution of the yield stress. Consequently, many models have been developed [31, 32, 38-40] in the form of an expression bi component: a component to describe the $\alpha$ mechanisms and another component to describe the $\beta$ mechanisms. A similar method is used in the works of Berthe et al. $[17,18]$ to describe the evolution of the linear behaviour with the strain rate. In their works Berthe et al. $[18,19]$ 
proposed to used a bi-spectral model to describe the different mechanisms involved from quasistatic to dynamic loadings. The viscoelastic spectral law used in $[17,18]$ decompose the viscous strain in elementary viscous mechanisms associated to a relaxation time. A bi-spectral model is introduced to take into account the influence of strain rate on the linear behaviour: one spectre to the quasi-static mechanisms and a second spectre to the dynamic mechanisms.

Assuming that a parallel can be done between the literature and the presented works, it is proposed to model the evolution of $\sigma_{t}$ with the strain rate thanks to a bi-sigmodal criterion, hence it is proposed to superpose two Goldberg's type functions, following the equation:

$$
\sigma_{t}=\sigma_{0}+\sigma_{d i f f_{1}} * \exp \left(c_{1} * \dot{\varepsilon}\right)+\sigma_{d i f f_{2}} * \exp \left(c_{2} * \dot{\varepsilon}\right)
$$

Since there was no available data at ambient temperature that reach the saturation value, an arbitrary value was taken which corresponds to the highest value obtained for all the tests including those at low temperature to obtain the $\sigma_{0}$ value. On the equation 5 , four parameters are necessary to describe the evolution of the transition stress with strain rate. To identify the proposed criterion parameters a least square optimization was done using PYTHON on every obtained stress transition and not on a mean value. In the Figure 4, the experimental transition shear stress values are compared with the transition shear stress obtained with the proposed criterion.

This criterion seems to be in agreement with the $\sigma_{t}$ experimental transition stress at ambient temperature, and describes pretty well the evolution of the transition shear stress on a large range of strain rates, from quasi-static to dynamic loadings. By analogy, the same work could be done to model the evolution of $\varepsilon_{t}$ with the strain rate. 


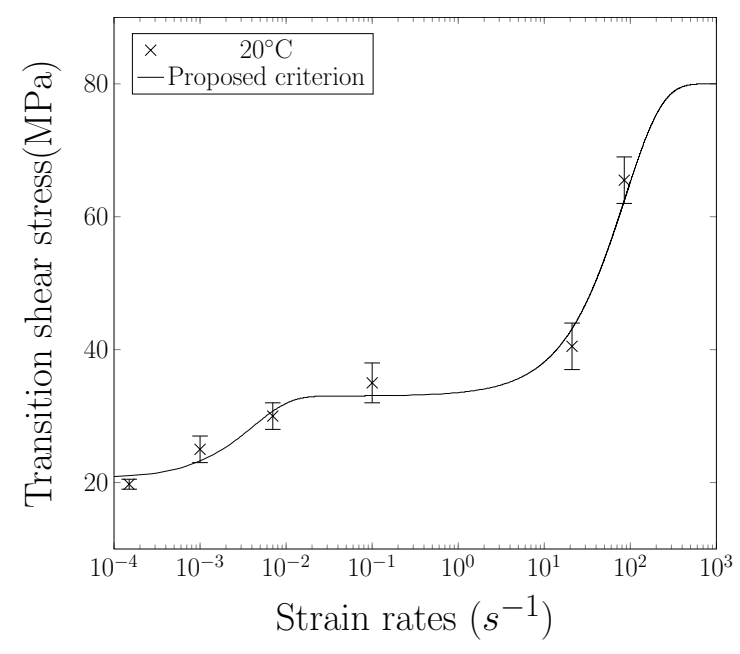

Figure 4: Application of the proposed criterion with the strain rates dependence to the $\sigma_{t}$ limit at ambient temperature for T700GC/M21

\begin{tabular}{ccccc}
\hline$\sigma_{0}(\mathrm{MPa})$ & $\sigma_{\text {diff }}(\mathrm{MPa})$ & $c_{1}$ & $\sigma_{\text {diff }}(\mathrm{MPa})$ & $c_{2}$ \\
\hline 80 & -13.5 & -181 & -45.7 & -110 \\
\hline
\end{tabular}

Table 1: Value of the parameters obtained with the optimization method

The proposed bi-sigmoidal model well describes the evolution of the $\sigma_{t}$ transition according to the strain rate and the mechanisms involved, but in previous works [1] the evolution of the $\sigma_{t}$ transition stress with the temperature was also pointed out. Therefore, it is now considered to take the temperature dependency into account in the transition stress evolution law. This is the aim of the next paragraph.

\subsection{Modelling of the effect of the temperature on the T700GC/M21 $\sigma_{t}$ and $\varepsilon_{t}$}

The influence of temperature on various criteria in composite literature is sparse, as shown in section 3. Therefore, to model the influence of temperature on the transition, the polymers literature has been considered to select possible solutions and particularly some works done by Richeton et al. [39, 40]. In these works, the authors proposed a strain rate and temperature dependent criterion for the yield stress for different polymers: PMMA, PC, etc. This criterion described the evolution of the yield stress under a wide range of temperature $\left(-40^{\circ} \mathrm{C}\right.$ to $\left.180^{\circ} \mathrm{C}\right)$. Richeton's model can be summarized by the following equation (6): 


$$
\sigma_{\text {yield }}=\sigma_{i}(0)-m * T+\frac{2 * k * T}{V} \sinh ^{-1}\left(\frac{\dot{\varepsilon}}{\dot{\varepsilon}_{0} * \exp \left(-\frac{\Delta H_{\beta}}{k * T}\right)}\right)
$$

Where $\sigma_{i}(0)$ is the internal stress at $0^{\circ} \mathrm{K}$. This parameter relies on the story of the material and the process used such as injection moulding, infusion or RTM. $\mathrm{m}$ is a material constant, $\mathrm{k}$ the Boltzmann constant, $\mathrm{V}$ an arbitrary activation volume, $\dot{\varepsilon}_{0}$ the constant pre-exponential strain rate and $\Delta H_{\beta}$ the $\beta$ activation energy. This model is a new formulation of the model proposed by Fotheringham and Cheery $[41,42]$. The adaptation proposed by Richeton et al. is based on the principle of the strain / rate temperature superposition principle of the yield stress described by Bauwens-Crowet et al. [35-37]. Richeton et al. also proposed to extend the model to describe the evolution of the yield stress above the glass transition.

The criterion proposed by Richeton et al. [39] is based on the physico-chemical properties of the resin material, and the model coefficients are expressed as functions of the activation energy of transition and the Boltzmann constant. For the material studied in these works some of these parameters are not directly available and are difficult to evaluate, such as the activation energy. To evaluate this parameter, a method has been proposed by Matadi Boumbimba et al. [26].

In the works presented, it is proposed to draw on the same general philosophy of the Richeton's model to build a temperature dependent model. To this end, the general structure of the equation was considered and particularly the temperature dependent terms. By analogy, the previous terms $\sigma_{d i f f_{1}}$ and $\sigma_{d i f f_{2}}$ are replaced by temperature dependent terms $\left(\frac{2 * T}{b}\right.$ and $\left.\frac{2 T}{e}\right)$. Moreover $c_{2}$ and $c_{3}$ are replaced by $\left(\frac{c}{T}\right)^{d}$ and $\left(\frac{f}{T}\right)^{g}$ in order to represent the $\exp \left(-\frac{\Delta H_{\beta}}{k * T}\right)$ term . The $\sigma_{0}$ term could also be modified in $\sigma_{0} * T$ but in the case presented here there is no information available about the temperature dependence of the highest transition stress, therefore the value of $\sigma_{0}$ was kept.

Finally the third criterion including the strain rate and temperature dependencies was described by (7):

$$
\sigma_{t}=\sigma_{0}-\frac{2 * T}{b} * \exp \left(-\left(\frac{c}{T}\right)^{d} * \dot{\varepsilon}\right)-\frac{2 * T}{e} * \exp \left(-\left(\frac{f}{T}\right)^{g} * \dot{\varepsilon}\right)
$$

To identify the parameter of the proposed criterion, it is chosen to consider that $\mathrm{g}=\mathrm{d}$, indeed there is not enough available data to identify the g parameter. As previously, the saturation 
value $\sigma_{0}$ corresponds to the highest value of the transition shear stress for all tests including those at low temperature. On the equation 7 , one may notice that only one parameter is added in comparison with the criterion strain rate dependent to take into account the temperature dependency. The parameters of this criterion were identified performing a least square optimization thanks to PYTHON software. The optimization was performed on all shear stress transitions obtained for each test and not on a mean value for each strain rates. The obtained parameters are summarized in Table 2 and the optimization result is plotted in Figure 5.

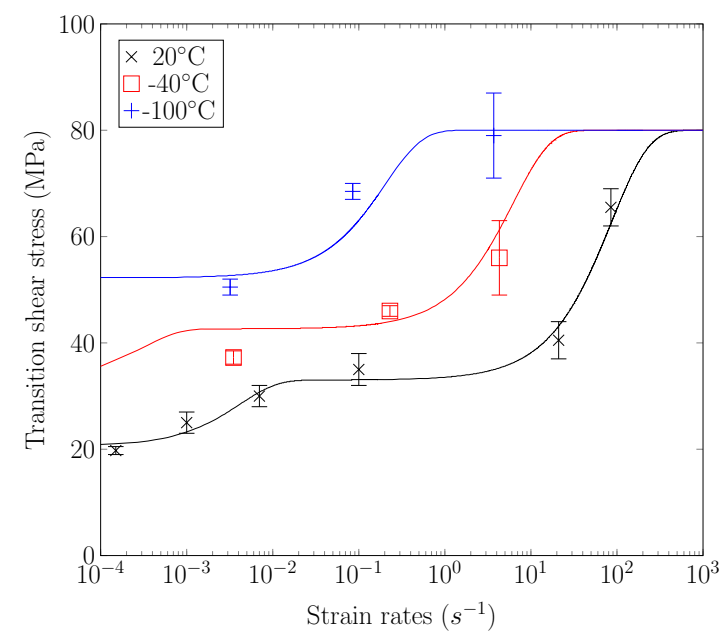

Figure 5: Application of the proposed criterion with the strain rate and temperature dependencies to the $\sigma_{t}$ transition at three temperatures for T700GC/M21

\begin{tabular}{cccccc}
\hline $\mathrm{a}(\mathrm{MPa})$ & $\mathrm{b}\left(\mathrm{K} \cdot M P a^{-1}\right)$ & $\mathrm{c}(\mathrm{K})$ & $\mathrm{d}$ & $\mathrm{e}\left(\mathrm{K} \cdot M P a^{-1}\right)$ & $\mathrm{f}(\mathrm{K})$ \\
\hline 80 & 47 & 473 & 11.5 & 12.5 & 199 \\
\hline
\end{tabular}

Table 2: Value of the parameters obtained with the optimization method

As a preliminary conclusion the proposed criterion seems to be in good agreement with the experimental data, and appears to be representative enough to describe all the phenomenology involved in the $\sigma_{t}$ evolution law according to the strain rate and temperature. The same works can be done to obtain an evolution law in terms of transition shear strain and the same conclusions can be done. 


\section{Conclusion}

In previous works [1], the $\sigma_{t}$ and $\varepsilon_{t}$, the transition shear stress or strain of the T700GC/M21 carbon/epoxy composite material, had been experimentally evaluated for six strain rates at ambient temperature and for three strain rates at $-40^{\circ} \mathrm{C}$ and $-100^{\circ} \mathrm{C}$. The influence of the strain rate and the temperature on these transitions has also been studied.

In the present work, a strain rate and temperature dependent criterion has been formulated to describe the transition shear stress or strain evolution law of the T700GC/M21 material. This criterion is only based on six parameters, and can take into account both the strain rate and the temperature dependencies. The proposed criterion allows to describe all the phenomenology involved in the evolution law of this shear stress or strain transition on a large range of strain rates and temperatures. This evolution law could be used in a behaviour law to describe the global behaviour of CFRP material. The proposed criterion is complex and includes six parameters but this criterion could be simplify to be used in a structural analysis.

\section{Acknowledgements}

The authors would like to thank the European Union, the French Government (MENRT, MoD), the DGA (French Armament Procurement Directorate), the DGAC (Civil Aviation General Direction), and the Nord-Pas de Calais Region (especially within the context of the CISIT project) for funding research studies and equipment that contributed to this research work.

\section{References}

[1] M. Castres, J. Berthe, E. Deletombe, M. Brieu, Experimental evaluation of the elastic limit of carbon-fibre reinforced epoxy composites under a large range of strain rate and temperature conditions, Strain 53 (6). doi:10.1111/str.12248.

URL http://dx.doi.org/10.1111/str.12248

[2] K. Morioka, Y. Tomita, K. Takigawa, High-temperature fracture properties of $\{\mathrm{CFRP}\}$ composite for aerospace applications, Materials Science and Engineering: A 319-321 (2001) 675-678. doi:http://dx.doi.org/10.1016/S0921-5093(01)01000-0.

URL http://www.sciencedirect.com/science/article/pii/S0921509301010000

[3] S. Cao, Z. Wu, X. Wang, Tensile properties of cfrp and hybrid frp composites at elevated temperatures, Journal of Composite Materials 43 (4) (2009) 315-330, cited By 69. doi:10.1177/0021998308099224.

[4] A. Gilat, R. K. Goldberg, G. D. Roberts, Experimental study of strain-rate-dependent behavior of carbon/epoxy composite, Composites Science and Technology 62 (10-11) (2002) 1469-1476. 
[5] C. Weeks, C. Sun, Modeling non-linear rate-dependent behavior in fiber-reinforced composites, Composites Science and Technology 58 (3) (1998) 603-611. doi:http://dx.doi.org/10.1016/S0266-3538(97)00183-8. URL http://www. sciencedirect.com/science/article/pii/S0266353897001838

[6] A. Nettles, E. Biss, Low temperature mechanical testing of carbon-fiber/epoxy-resin composite materials, Tech. rep., NASA/Marshall Space Flight Center Center/MSFC,Alabama (1996).

[7] I. Daniel, B. Werner, J. Fenner, Strain-rate-dependent failure criteria for composites, Composites Science and Technology 71 (3) (2011) 357-364.

[8] T. G. del Río, E. Barbero, R. Zaera, C. Navarro, Dynamic tensile behaviour at low temperature of cfrp using a split hopkinson pressure bar, Composites Science and Technology 65 (1) (2005) 61 - 71.

[9] I. M. Daniel, J.-M. Cho, B. T. Werner, J. S. Fenner, Characterization and constitutive modeling of composite materials under static and dynamic loading, AIAA journal 49 (8) (2011) 1658-1664.

[10] H. Hsiao, I. Daniel, Strain rate behavior of composite materials, Composites Part B: Engineering 29 (5) (1998) 521-533. doi:http://dx.doi.org/10.1016/S1359-8368(98)00008-0.

URL http://www.sciencedirect.com/science/article/pii/S1359836898000080

[11] J. F. Maire, Etudes thorique et exprimentale du comportement de matriaux composites en contraintes planes, Ph.D. thesis, U.F.R des sciences et techniques de l'universit de Franche-Comt (1992).

[12] F. Laurin, Approche multiéchelle des mécanismes de ruine progressive des matériaux stratifiés et analyse de la tenue de structures composites, Ph.D. thesis (2005).

[13] P. Ladeveze, E. LeDantec, Damage modelling of the elementary ply for laminated composites, Composites Science and Technology 43 (3) (1992) 257 - 267. doi:http://dx.doi.org/10.1016/0266-3538(92)90097-M. URL http://www.sciencedirect.com/science/article/pii/026635389290097M

[14] P. Ladevze, G. Lubineau, On a damage mesomodel for laminates: micromechanics basis and improvement, Mechanics of Materials 35 (8) (2003) 763 - 775, multi-scale Modeling of Materials. doi:http://dx.doi.org/10.1016/S0167-6636(02)00204-1.

URL http: //www.sciencedirect.com/science/article/pii/S0167663602002041

[15] J. Maire, J. Chaboche, A new formulation of continuum damage mechanics (cdm) for composite materials, Aerospace Science and Technology 1 (4) (1997) 247 - 257. doi:http://dx.doi.org/10.1016/S12709638(97)90035-3.

URL http://www.sciencedirect.com/science/article/pii/S1270963897900353

[16] D. Lévêque, Analyse de la tenue au dlaminage des composites stratifis: identification d'un modle d'interface interlaminaire., Ph.D. thesis, Ecole Normale Suprieure de Cachan, Laboratoire de Mcanique et technologie (1998).

[17] J. Berthe, M. Brieu, E. Deletombe, Improved viscoelastic model for laminate composite under static and dynamic loadings, Journal of Composite Materials 47 (14) (2013) 1717-1727. arXiv:http://dx.doi.org/10.1177/0021998312451294, doi:10.1177/0021998312451294.

URL http://dx.doi .org/10.1177/0021998312451294

[18] J. Berthe, M. Brieu, E. Deletombe, G. Portemont, Temperature effects on the time dependent viscoelastic behaviour of carbon/epoxy composite materials: Application to T700GC/M21, Materials and Design 62 
(2014) 241-246.

[19] J. Berthe, Comportement thermo-visco-lastique des composites CMO-de la statique la dynamique grande vitesse, Ph.D. thesis, ONERA/Laboratoire Mcanique de Lille/ EDSPI 072 (2013).

[20] I. M. Daniel, J.-J. Luo, P. M. Schubel, B. T. Werner, Interfiber/interlaminar failure of composites under multi-axial states of stress, Composites Science and Technology 69 (6) (2009) $764-771$.

[21] L. Raimondo, L. Iannucci, P. Robinson, P. Curtis, Modelling of strain rate effects on matrix dominated elastic and failure properties of unidirectional fibre-reinforced polymer-matrix composites, Composites Science and Technology 72 (7) (2012) 819-827. doi:http://dx.doi.org/10.1016/j.compscitech.2012.02.011.

URL http://www.sciencedirect.com/science/article/pii/S026635381200070X

[22] Y. Tao, H. Chen, K. Yao, H. Lei, Y. Pei, D. Fang, Experimental and theoretical studies on inter-fiber failure of unidirectional polymer-matrix composites under different strain rates, International Journal of Solids and Structures (2016) -doi:http://dx.doi.org/10.1016/j.ijsolstr.2016.11.014.

URL http://www.sciencedirect.com/science/article/pii/S0020768316303390

[23] F. Laurin, N. Carrre, J.-F. Maire, A multiscale progressive failure approach for composite laminates based on thermodynamical viscoelastic and damage models, Composites Part A: Applied Science and Manufacturing 38 (1) (2007) 198 - 209. doi:http://dx.doi.org/10.1016/j.compositesa.2006.01.018.

URL http://www.sciencedirect.com/science/article/pii/S1359835X0600025X

[24] C. Huchette, Sur la complmentarit des approches exprimentales et numriques pour la modlisation des mcanismes d'endommagement des composites stratifis, Ph.D. thesis, Universit Paris VI (2005).

[25] R. M. Boumbimba, S. Ahzi, N. Bahlouli, D. Ruch, J. Gracio, Dynamic mechanical properties of pmma/organoclay nanocomposite: experiments and modeling, Journal of Engineering Materials and Technology 133 (3) (2011) 030908.

[26] R. M. Boumbimba, K. Wang, N. Bahlouli, S. Ahzi, Y. Rmond, F. Addiego, Experimental investigation and micromechanical modeling of high strain rate compressive yield stress of a melt mixing polypropylene organoclay nanocomposites, Mechanics of Materials 52 (2012) 58-68.

[27] K. Wang, S. Ahzi, R. M. Boumbimba, N. Bahlouli, F. Addiego, Y. Rmond, Micromechanical modeling of the elastic behavior of polypropylene based organoclay nanocomposites under a wide range of temperatures and strain rates/frequencies, Mechanics of Materials 64 (2013) 56 - 68. doi:http://dx.doi.org/10.1016/j.mechmat.2013.04.009.

URL http://www.sciencedirect.com/science/article/pii/S0167663613000653

[28] R. Gerlach, C. Siviour, N. Petrinic, J. Wiegand, Experimental characterisation and constitutive modelling of RTM-6 resin under impact loading, Polymer 49 (2008) 2728-2737.

[29] J. L. Jordan, J. R. Foley, C. R. Siviour, Mechanical properties of epon 826/dea epoxy, Mechanics of TimeDependent Materials 12 (3) (2008) 249-272.

[30] R. K. Goldberg, D. C. Stouffer, Strain rate dependent analysis of a polymer matrix composite utilizing a micromechanics approach, Journal of Composite Materials 36 (7) (2002) 773-793.

[31] A. Mulliken, M. Boyce, Low to high strain rate deformation of amorphous polymers, in: Proceedings of the 2004 SEM X International Congress and Exposition on Experimental and Applied Mechanics, 2004, pp. 
$7-10$.

[32] A. Mulliken, M. Boyce, Mechanics of the rate-dependent elastic-plastic deformation of glassy polymers from low to high strain rates, International Journal of Solids and Structures 43 (5) (2006) 1331-1356.

[33] N. A. Hazeg, Contribution à l'étude des phénomènes de relaxation et de vieillissement dans les polymères amorphes, Ph.D. thesis, thèse de doctorat dirigée par Cunat, Christian Mécanique et énergétique Vandoeuvreles-Nancy, INPL 2006 (2006).

URL http: //www . theses.fr/2006INPL010N

[34] J. G. Williams, The beta relaxation in epoxy resin-based networks, Journal of Applied Polymer Science 23 (12) (1979) 3433-3444.

[35] C. Bauwens-Crowet, J. C. Bauwens, G. Homès, Tensile yield-stress behavior of glassy polymers, Journal of Polymer Science Part A-2: Polymer Physics 7 (4) (1969) 735-742.

[36] C. Bauwens-Crowet, J. C. Bauwens, G. Homès, The temperature dependence of yield of polycarbonate in uniaxial compression and tensile tests, Journal of Materials Science 7 (2) (1972) 176-183. doi:10.1007/BF02403504.

URL https : //doi .org/10.1007/BF02403504

[37] C. Bauwens-Crowet, The compression yield behaviour of polymethyl methacrylate over a wide range of temperatures and strain-rates, Journal of Materials Science 8 (7) (1973) 968-979. doi:10.1007/BF00756628. URL http://dx .doi .org/10.1007/BF00756628

[38] C. Bauwens-Crowet, J.-C. Bauwens, Effect of thermal history on the tensile yield stress of polycarbonate in the transition range, Polymer 24 (7) (1983) 921 - 924. doi:http://dx.doi.org/10.1016/0032-3861(83)90215X.

URL http://www.sciencedirect.com/science/article/pii/003238618390215X

[39] J. Richeton, S. Ahzi, L. Daridon, Y. Rmond, A formulation of the cooperative model for the yield stress of amorphous polymers for a wide range of strain rates and temperatures, Polymer 46 (16) (2005) 6035-6043.

[40] J. Richeton, S. Ahzi, K. Vecchio, F. Jiang, R. Adharapurapu, Influence of temperature and strain rate on the mechanical behavior of three amorphous polymers: Characterization and modeling of the compressive yield stress, International Journal of Solids and Structures 43 (7-8) (2006) 2318-2335.

[41] D. Fotheringham, B. Cherry, C. Bauwens-Crowet, Comment on the compression yield behaviour of polymethyl methacrylate over a wide range of temperatures and strain-rates, Journal of Materials Science 11 (7) (1976) 1368-1371.

[42] D. Fotheringham, B. Cherry, The role of recovery forces in the deformation of linear polyethylene, Journal of materials science 13 (5) (1978) 951-964. 


\section{List of Figures}

$1 \sigma_{t}$ and $\varepsilon_{t}$ at three different temperatures for $\left[ \pm 45^{\circ}\right]_{s} \mathrm{~T} 700 \mathrm{GC} / \mathrm{M} 21 \ldots \ldots$

2 Comparison between experimental $\sigma_{t}$ of the T700GC/M21 at ambient temperature and models of the literature . . . . . . . . . . . . . 5

3 Application of the Gerlach criterion to the $\sigma_{t}$ limit at ambient temperature for

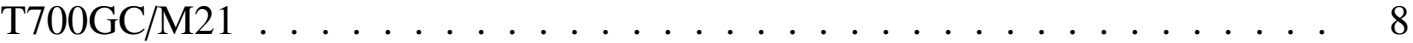

4 Application of the proposed criterion with the strain rates dependence to the $\sigma_{t}$ limit at ambient temperature for T700GC/M21 . . . . . . . . . . . . . 10

5 Application of the proposed criterion with the strain rate and temperature dependencies to the $\sigma_{t}$ transition at three temperatures for T700GC/M21 . . . 12 


\section{List of Tables}

1 Value of the parameters obtained with the optimization method . . . . . . 10

2 Value of the parameters obtained with the optimization method . . . . . . . . 12 